MAIA, M.C.C.; PEDROSA, J.F.; TORRES FILHO, J.; NEGREIROS, M.Z. de; BEZERRA NETO, F. Características de qualidade de cebola múltipla durante armazenamento sob condição ambiental não controlada. Horticultura Brasileira, Brasília, v. 18, n. 1, p. 61-64, março 2.000.

\title{
Características de qualidade de cebola múltipla durante armazenamento sob condição ambiental não controlada.
}

\author{
Maria C. C. Maia采, Josué F. Pedrosa ${ }^{2}$; José Torres Filho ${ }^{2}$; Maria Z. de Negreiros ${ }^{2}$; Francisco Bezerra Neto ${ }^{2}$.
}

${ }^{2}$ ESAM. C. Postal 137. CEP 59.625 - 900. Mossoró - RN.

\begin{abstract}
RESUMO
Utilizando-se progênies de meios irmãos de cebola múltipla, foram avaliados caracteres de qualidade de bulbos durante o armazenamento pós-colheita sob condição de ambiente natural. Para tanto, foi conduzido um experimento em condições de laboratório, utilizando delineamento inteiramente casualizado, com 14 tratamentos (progênies) e três repetições. Os conteúdos de sólidos solúveis e matéria seca foram influenciados significativamente pelo tempo de armazenamento. A perda de peso máxima foi $21,70 \%$ em cinco semanas.
\end{abstract}

Palavras-chave: Allium cepa L., pós - colheita, qualidade.

\begin{abstract}
Characteristics of multiplier onion during controlled storage conditions.

Bulb quality characteristics from multiplier onion half-sib families were evaluated during postharvest storage under natural ambient conditions. For this purpose, one experiment was conducted under laboratory conditions. The experiment was carried out in a completely randomized design with 14 treatments (families) and three replications. Soluble solid and dry matter contents were significantly influenced by storage period. Maximum weight loss was $21.7 \%$ within five weeks.
\end{abstract}

Keywords: Allium cepa L., postharvest, quality.

(Aceito para publicação em 17 de fevereiro de 2.000)

$\mathrm{A}$ cebola (Allium cepa L.) é uma hortaliça amplamente consumida em todo o mundo e o seu cultivo é expressivo no Brasil onde se tem observado um incremento contínuo na área plantada. Em 1993, a produção de cebolas no Brasil foi de 928.704 toneladas, ocupando o terceiro lugar em importância econômica (Anuário...,1995).

Para Costa \& Pinto (1977), o Rio Grande do Norte apresenta grande potencial para a exportação de cebola para o Mercado Comum Europeu. Sua produção se dá no verão, possibilitando a maturidade, geralmente acentuada, tornando a cura fácil e as condições de armazenamento satisfatórias, sendo consequentemente os bulbos de excelente qualidade.

Na espécie existe grande diversidade de tipos, sendo que o grupo aggregatum G. Don. tem-se tornado comercialmente importante para o país, especialmente para as regiões norte, nordeste e sudeste, sendo utilizada no preparo de pratos típicos regionais. De acordo com Jones \& Mann (1963), esse grupo se caracteriza por apresentar bulbos com numerosos brotos laterais; inflorescência tipicamente sem bulbinhos, podendo ou não produzir sementes, propagando-se sexuada ou vegetativamente pelos bulbos laterais. O tipo produzido no Rio Grande do Norte possui coloração roxa devido à presença de fenóis (catecol e pirocatecol) em sua composição química, precursores dos pigmentos, e está ligada à resistência aos fungos Colletotrichum sp. e Botrytis spp (Costa \& Pinto, 1977).

O período de armazenamento depende das características genéticas da variedade, condições e tempo de armazenamento, junto a outros fatores, inclusive método de colheita e cura. Estudos dos fatores que determinam aumentos no período de armazenamento da cebola suscitam muitas perguntas. As publicações deste assunto refletem a complexidade do problema.

As alterações que ocorrem na cebola após a colheita, e que dificultam a conservação são decorrentes da perda de água, brotação, enraizamento e deterioração (Santos \& Araújo, 1993). De acordo com Ward (1976), a perda de peso em cebola armazenada sob temperatu- ras altas aumenta principalmente em função do aumento da respiração ou perda de água.

A variedade de cebola múltipla pode apresentar uma vida útil pós colheita consideravelmente prolongada se estocada sob condições de armazenamento favoráveis. Associado a isso, inúmeros fatores, como procedimentos técnicos, características do genótipo, adequação no transporte, pequenas distâncias e tempo para a colocação do produto nos mercados podem minimizar as perdas do produto.

A composição química dos bulbos de cebola é variável. O conteúdo de matéria seca mostra desde teores baixos, cerca de $4 \%$ até cerca de $25 \%$ em algumas cultivares, sendo que a maior parte da matéria seca é constituída por carboidratos (Jones \& Mann, 1963). Teores de matéria seca variando de 7,62 a $9,13 \%$, foram observados por Vavrina \& Smittle (1993), quando estudaram o efeito do ambiente na qualidade dos bulbos de 6 cultivares de cebola comum.

Geralmente o teor de matéria seca pode aumentar quando as cebolas são colhidas manualmente com a haste

\footnotetext{
${ }^{1}$ Bolsista da Capes
} 
intacta e com o tempo de armazenamento (Smittle \& Maw, 1988).

Lorenz \& Hoyle (1946), estudando o efeito do tempo de cura sobre a perda de peso e composição química de bulbos de cebolas inferiram que o incremento no teor de matéria seca nos bulbos de cebola após período de cura é devido a uma remoção de água dos bulbos juntamente com o movimento de substâncias, principalmente a translocação de açúcares da parte aérea para os bulbos. Smittle et al., (1979) avaliando características de qualidade em cebolas, já haviam reportado que o teor de matéria seca aumenta com o período de armazenamento.

A qualidade de estocagem é extremamente importante em cebola quando os bulbos são mantidos por um longo período de tempo sob condições ambientais naturais. Longo período de armazenamento e alta percentagem de matéria seca se inserem numa mesma categoria interferindo na qualidade e no teor de sólidos solúveis totais (Pike, 1986).

A capacidade que essa cultura possui de apresentar poucas alterações nas suas características físicas e químicas durante o armazenamento pode determinar sua potencialidade comercial e aceitabilidade, possibilitando minimizar as perdas pós colheita. Apesar da inquestionável importância que assume esse aspecto de conservação, inexistem investigações sobre as perdas que ocorrem com a cebola múltipla colhida no Rio Grande do Norte.

O objetivo desse trabalho foi avaliar caracteres de qualidade (perda de peso, sólidos solúveis e matéria seca) durante armazenameto pós-colheita, utilizandose de progênies de meios irmãos de cebola múltipla.

\section{MATERIAL E MÉTODOS}

As 14 progênies de meios irmãos avaliadas neste trabalho foram plantadas na horta do Departamento de Fitotecnia da Escola Superior de Agricultura de Mossoró (ESAM), no período de junho a setembro de 1997, em solo classificado como Podzólico Vermelho-Amarelo Equivalente Eutrófico, textura francoarenosa, PE (Eutrustalfs), segundo o Soil Taxonomy, Estados Unidos (1979).

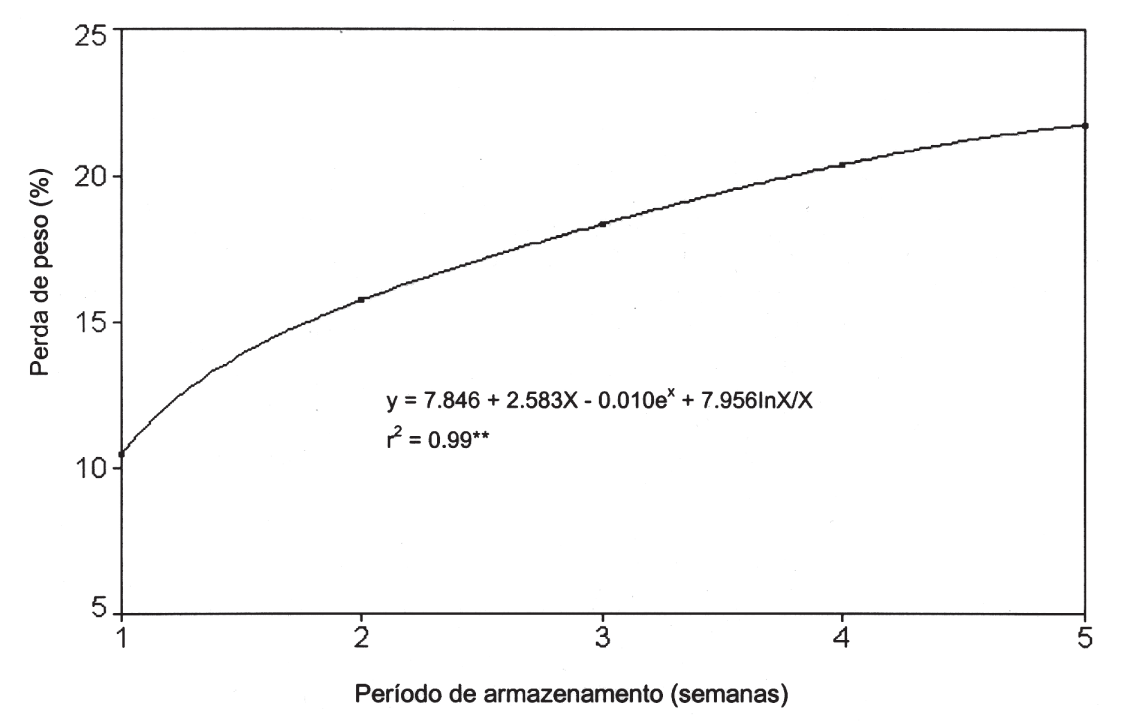

Figura 1. Perda de peso de bulbos de cebola múltipla armazenados durante 5 semanas. Mossoró, ESAM, 1998.

O experimento foi conduzido no laboratório de Pós-Colheita da ESAM, nos meses de setembro e outubro de 1997. As condições ambientais de armazenagem foram de temperatura média $27,4^{\circ} \mathrm{C} \pm 2^{\circ} \mathrm{C}$ e umidade relativa média do ar $69,5 \% \pm 2 \%$.

As plantas de cada parcela útil foram colhidas com a parte aérea intacta nas primeiras horas do dia, aos 96 dias do transplantio, quando no mínimo, $80 \%$ das plantas de cada parcela apresentavam sinais de maturação, isto é, por ocasião do tombamento da haste e secagem inicial das folhas.

A cura dos bulbos se deu de forma natural, com a exposição diária ao sol, até se observar seca completa de suas folhas, a qual ocorreu após uma semana. Após a cura, foram levados ao laboratório de pós-colheita da ESAM, onde permaneceram armazenados sob condição ambiental não modificada, com a parte aérea intacta, sob folhas de papel em balcões de alvenaria durante cinco semanas.

Utilizou-se o delineamento inteiramente casualizado, com 14 tratamentos e três repetições. Cada repetição foi composta por 24 bulbos. Os dados foram analisados semanalmente.

Avaliou-se a perda de peso considerando-se seis épocas a partir da cura, por meio da diferença entre o peso Inicial do bulbo e o peso obtido a cada intervalo de amostragem utilizando-se cinco bulbos de cada parcela útil, mantidas sob temperatura ambiente por um período de 35 dias. O teor de matéria seca, expresso em percentagem, foi determinado após a secagem de uma amostra de cinco bulbos, em estufa com circulação forçada de ar e temperatura constante a $70^{\circ} \mathrm{C}$. O teor de sólidos solúveis foi determinado por refratometria ( $\left.{ }^{\circ} \mathrm{BRIX}\right)$, utilizando-se um refratômetro digital, em suco extraído através de "espremedor de limão" utilizando uma fatia da porção mediana do bulbo, sem película e camada mais externa, considerando uma amostra de cinco bulbos por parcela, expressa em porcentagem. $\mathrm{O}$ peso fresco dos bulbos foi determinado a partir de pesagem de uma amostra de cinco bulbos, em balança de precisão, sendo expresso em gramas.

Os dados foram submetidos à análise de regressão utilizando-se o programa 'Table Curve'.

\section{RESULTADOS E DISCUSSÃO}

Registrou-se uma perda de peso média de $17,41 \%$ durante o período de 35 dias de armazenamento. Considerando que a cebola é comercializada por unidade de peso, a perda de peso total se constitui num fator limitante na vida de armazenamento do produto, refletindo-se em sérios prejuízos econômicos. A perda de peso média diária foi de $0,62 \%$ durante o período em que as plantas foram armazenadas. Com relação ao período de armazenamento (Figura 1), 


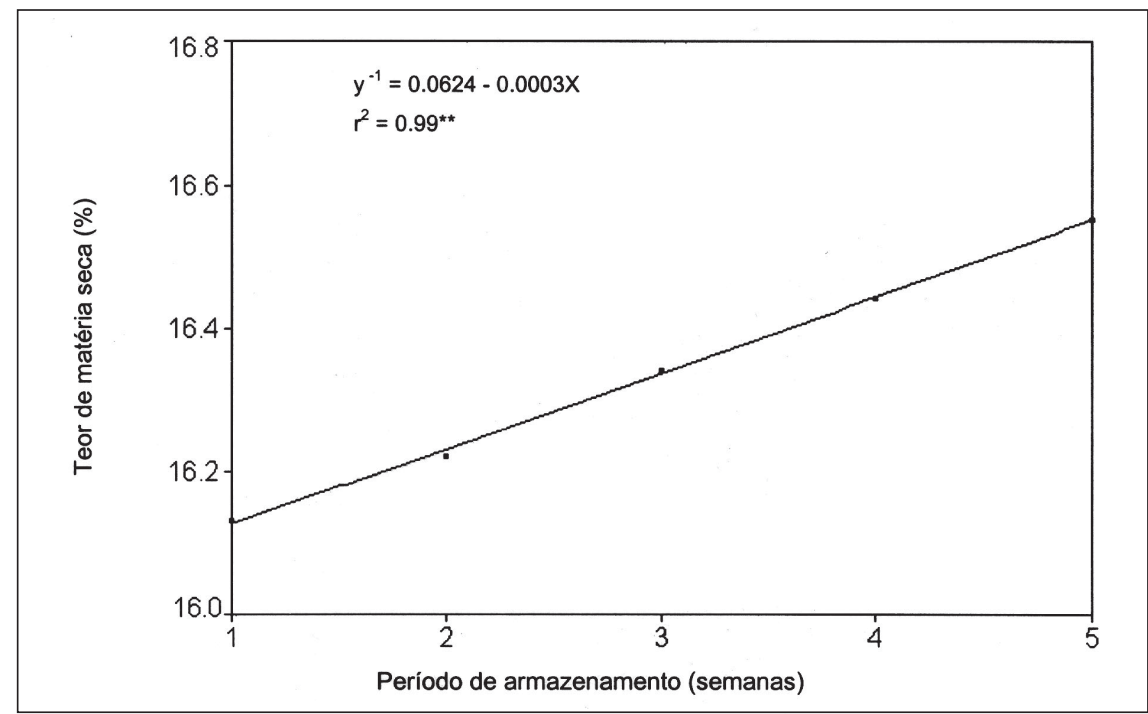

Figura 2. Teor de matéria seca de bulbos de cebola múltipla armazenados durante 5 semanas. Mossoró, ESAM, 1998.

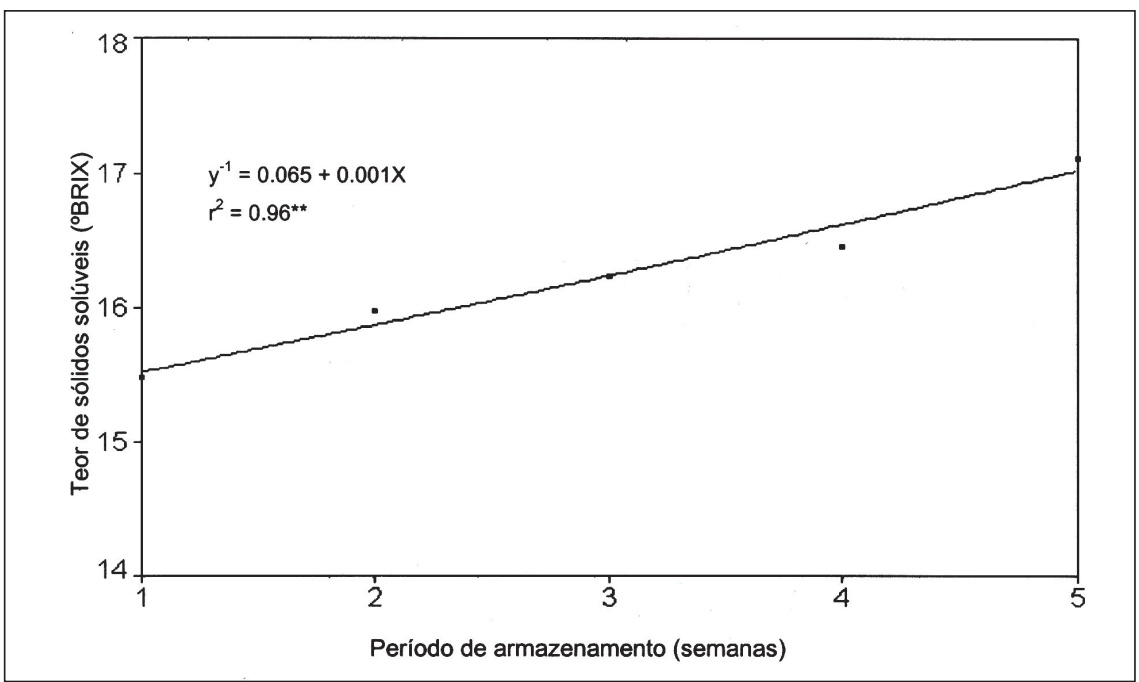

Figura 3. Teor de sólidos solúveis de bulbos de cebola múltipla armazenados durante 5 semanas. Mossoró, ESAM, 1998.

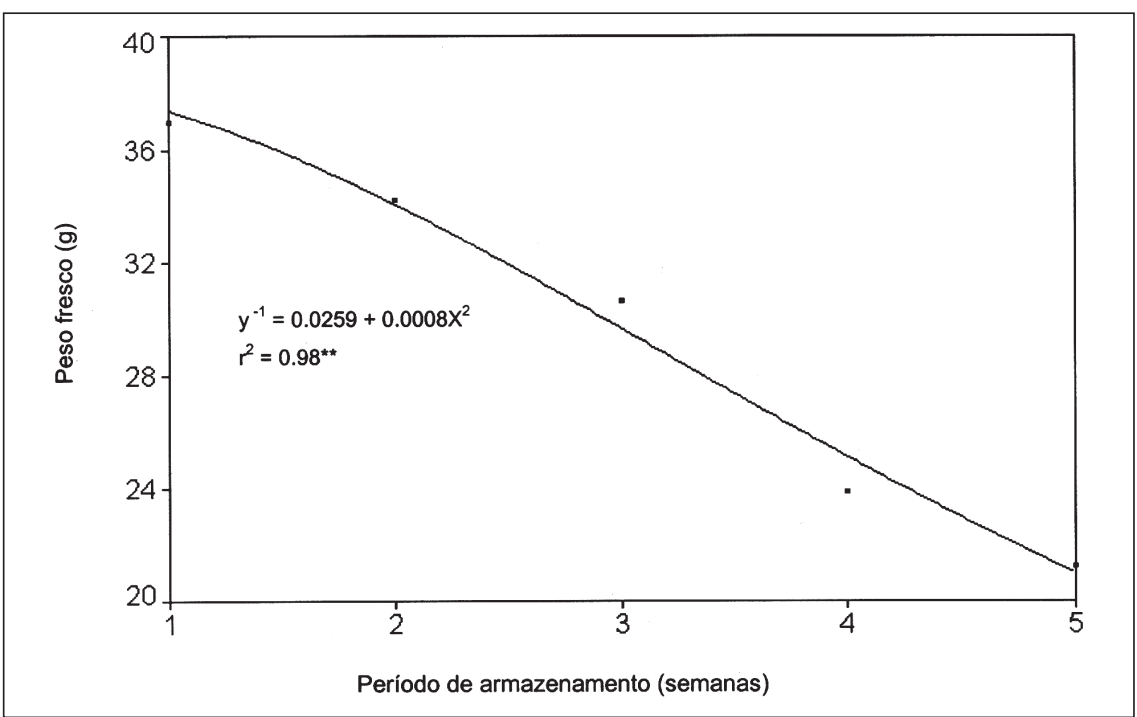

Figura 4. Peso fresco de bulbos de cebola múltipla armazenados durante 5 semanas. Mossoró, ESAM, 1998. observou-se um aumento linear na perda de peso, sendo mais rápido até a $2^{\mathrm{a}}$ semana. A partir daí, notou-se um crescimento mais lento, com perda progressiva em peso total. Com o decorrer do tempo de armazenamento, alcançou $21,70 \%$, no fim da 5는 semana. Todas as perdas, provavelmente, ocorreram devido à desidratação e à taxa de respiração, estimuladas por altas temperaturas $\left(27,4 \pm 2{ }^{\circ} \mathrm{C}\right)$, uma vez que as taxas de deterioração, enraizamento e brotação foram desprezíveis.

Foi verificado um teor de matéria seca variando de 16,13 a $16,55 \%$ no decorrer do período de armazenamento. A desidratação dos bulbos, juntamente com o movimento vertical de substâncias, predominantemente carboidratos, da parte aérea para os bulbos são os principais fatores que contribuem para o incremento do teor de matéria seca nos bulbos armazenados com a haste intacta Lorenz \& Hoyle (1946). O teor de matéria seca apresentou um acréscimo linear com o tempo de armazenamento (Figura 2), a translocação de solutos da parte aérea para os bulbos, juntamente com a perda de água, parece ter tido maior influência no aumento percentual de matéria seca. Cebolas que apresentam elevado teor de sólidos solúveis totais são desejáveis e de grande aceitabilidade, sendo seu destino a comercialização 'in natura' ou, principalmente, para a indústria de desidratação, pois esse índice é considerado uma importante característica de qualidade.

O teor de sólidos solúveis totais, na $1^{\text {a }}$ semana de armazenamento, apresentou um alto valor médio de $15,47 \%$. Durante o período de armazenamento, o teor de sólidos solúveis totais alcançou um valor médio de $16,25 \%$. Isso indica que houve um acréscimo no percentual de sólidos solúveis totais com o tempo de armazenamento conferindo melhor qualidade ao produto. Ao fim da 5a semana em que os bulbos foram armazenados com a parte aérea intacta, verificou-se um incremento linear na percentagem de sólidos solúveis totais (Figura 3). A composição desse parâmetro é formada essencialmente por açúcares, sendo que o aumento dessas substâncias com o tempo de armazenamento, é devido à remoção de 
água dos bulbos, e principalmente, à translocação de açucares da parte aérea para os bulbos.

Para o peso fresco de bulbos foram encontrados valores variando entre $36,95 \mathrm{~g}$, observados na $1^{\mathrm{a}}$ semana, a $21,18 \mathrm{~g}$, ao final da $5^{\mathrm{a}}$ semana de armazenamento. A média durante o período foi de 29,33 g. Registrou-se diminuição no peso fresco em relação ao peso inicial, mais acentuada a partir da 3a semana de armazenamento (Figura 4), indicando ser esse o período máximo quando se deseja armazenar cebolas sob condição ambiental com altas temperaturas. A desidratação e a respiração parecem ser os principais fatores responsáveis por essa perda progressiva.

Conclui-se que a perda de peso máxima em cinco semanas foi de $21,70 \%$, que o tempo de armazenamento influen- ciou significativamente na elevação dos teores de matéria seca e sólidos solúveis totais e que o peso fresco de bulbos diminuiu ao longo do período de armazenamento.

\section{LITERATURA CITADA}

ANUÁRIO ESTATÍSTICO DO BRASIL. Rio de Janeiro: IBGE, v. 55, 1995.

COSTA, C.P. da; PINTO, C.A.B.P. Melhoramento de Cebola. In: Melhoramento de hortaliças. Piracicaba, SP: ESALQ, 1977.n.p.

JONES, H.H.; MANN, L.K. Onion and their allies. New York: Leonard Hillbooks. 1963. $286 \mathrm{p}$.

LORENZ, O.A.; HOYLE, B. J. Effect of curing and time of topping on weight loss and chemical composition of onion bulbs. Proceedings of the American Society for. Horticultural Science. v. 47, p. 301-308.

PIKE, L.M. Onion Breeding. In: BASSETT, M.J Breeding Vegetable Crops. Florida, Avi Publishing Company, p. 357-392. 1986.
SANTOS, R.F.A. de; ARAÚJO, M.T. de. Conservação pós-colheita da cebola $\varnothing$ São Paulo $\varnothing$. Horticultura Brasileira, Brasília, v. 11, n. 1, p. 41-42, 1993.

SMITTLE, D.A.; HAYES, W.L.; DICKENS, W.L. Quality evaluation of onion. Georgia Agricultural. Experimentation Station. Research, p. 336. 1979.

SMITTLE, D.A.; M.A.W, B.W. Effects of maturity and harvest methods on storage and quality of onions. HortScience, v. 23, n. 1, p. 141-143, 1988.

USA. Department of Agriculture Soil Taxonomy. A basic system of soil classification for making and interpreting soil survys. Washinton, Department of Agriculture, p. 754,1975. (Agriculture Handbook, 436).

VAVRINA, C.S.; SMITTLE, D.A. Evaluating sweet onion cultivars for sugar concentrations and pungency. HortScience, v. 28, n. 8, p. 804806, 1993.

WARD, C.M. The influence of temperature on weight loss from stored onion bulbs due to desiccation, respiration and sprouting. Annals of Applied Biology, v. 83, p. 149-155, 1976. 